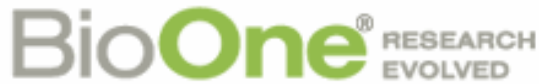

\section{Effects of Aqueous Smoke and Nitrate Treatments on Germination of 12 Eastern Mediterranean Basin Plants}

Author(s): Şükrü Serter Çatav, Köksal Küçükakyüz, Çağatay Tavşanoğlu \& Kenan Akbaş

Source: Annales Botanici Fennici, 52(1-2):93-100.

Published By: Finnish Zoological and Botanical Publishing Board

DOI: http://dx.doi.org/10.5735/085.052.0211

URL: http://www.bioone.org/doi/full/10.5735/085.052.0211

BioOne (www.bioone.org) is a nonprofit, online aggregation of core research in the biological, ecological, and environmental sciences. BioOne provides a sustainable online platform for over 170 journals and books published by nonprofit societies, associations, museums, institutions, and presses.

Your use of this PDF, the BioOne Web site, and all posted and associated content indicates your acceptance of BioOne's Terms of Use, available at www.bioone.org/page/ terms of use.

Usage of BioOne content is strictly limited to personal, educational, and non-commercial use. Commercial inquiries or rights and permissions requests should be directed to the individual publisher as copyright holder. 


\title{
Effects of aqueous smoke and nitrate treatments on germination of 12 eastern Mediterranean Basin plants
}

\author{
Şükrü Serter Çatav ${ }^{1, *}$, Köksal Küçükakyüz¹, Çağatay Tavşanoğlu² \& \\ Kenan Akbaş ${ }^{1}$
}

1) Department of Biology, Muğla Sıtkı Koçman University, Kötekli 48000, Muğla, Turkey
('corresponding author's e-mail: sertercatav@mu.edu.tr)
2) Fire Ecology and Seed Research Lab., Division of Ecology, Department of Biology, Hacettepe
University, Beytepe 06800, Ankara, Turkey

Received 26 Aug. 2014, final version received 1 Oct. 2014, accepted 3 Oct. 2014

Çatav Ş.S., Küçükakyüz K., Tavşanoğlu Ç. \& Akbaş K. 2015: Effects of aqueous smoke and nitrate treatments on germination of 12 eastern Mediterranean Basin plants. - Ann. Bot. Fennici 52: 93-100.

Determining the relative role of various cues on seed germination in Mediterranean plants is important to understanding their response to variable conditions. We studied germination responses of 12 eastern Mediterranean Basin species (Alyssum caricum, A. minus, Carthamus dentatus, Daucus broteri, D. carota, Hypericum aviculariifolium, Muscari comosum, Onopordum caricum, Rumex crispus, Sarcopoterium spinosum, Silene vulgaris, Smyrnium rotundifolium) to different smoke and nitrate concentrations in laboratory. Smoke treatments resulted in significant increase in germination of D. carota, O. caricum, and S. spinosum, but had a negative effect on germination of Hypericum aviculariifolium. Of the 12 studied species, five showed significant improvement in germination after at least one of the nitrate treatments compared with the control. In total, smoke and nitrate treatments significantly increased the germination percentage in six of the 12 studied species. All the species that have smoke- and/or nitrate-stimulated germination were propagule-persisters $(\mathrm{P}+)$, able to recruit after fire. The results reveal that both smoke and nitrate improve germination of Mediterranean species. Our results also suggest the presence of species-specific germination response to smoke and nitrate in Mediterranean plants.

\section{Introduction}

Fire is a common disturbance that has an significant impact on the structure and function of plant communities (Verdú \& Pausas 2007, Keeley et al. 2012). Many plant species have evolved traits or mechanisms allowing their persistence after fire. Examples of such mechanisms include resprouting, serotiny and fire-stimulated germination (Keeley et al. 2011). The latter is the result of dormancy-breaking effects of heat (Thanos et al. 1992, Herranz et al. 1998, Moreira \& Pausas 2012) and chemical compounds found in charred wood (Keeley et al. 1985, Keeley \& Bond 1997) and smoke (De Lange \& Boucher 1990, Dixon et al. 1995, Moreira et al. 2010). In addition to its important role in stimulating seed germination, it has been demonstrated that chemical compounds in smoke also enhance seedling growth (Van Staden et al. 2006, Moreira et al. 2010), 
flowering (Keeley 1993), somatic embryogenesis (Senaratna et al. 1999) and pollen germination as well as tube elongation (Papenfus et al. 2014). Consequently, stimulation of germination and seedling growth by fire-produced smoke plays a key role in plant recruitment (Tormo et al. 2014).

Soils of Mediterranean-type ecosystems are usually characterized by their low nutrient content (Rundel 1982, Cowling et al. 1996, Wisheu et al. 2000). In these ecosystems, concentrations of nitrogenous compounds in the soil (e.g., ammonium and nitrate) increase after fires (Arianoutsou-Faraggitaki \& Margaris 1982, Stock \& Lewis 1986, Christensen 1994). The increase of these compounds in nutrient-poor Mediterranean habitats may play an important role in regulation of post-fire germination (Thanos \& Rundel 1995, Bell et al. 1999, Henig-Sever et al. 2000).

Effects of smoke on seed germination of Mediterranean Basin plants have received more attention in recent years (Crosti et al. 2006, Reyes \& Trabaud 2009, Moreira et al. 2010, Çatav et al. 2014, Tormo et al. 2014). However, there is limited information about the effect of nitrate on seed germination, with the exception of few studies conducted in the Mediterranean Basin (Doussi \& Thanos 1997, Henig-Sever et al. 2000, Pérez-Fernández \& Rodríguez-Echeverría 2003, Pérez-Fernández et al. 2006, Luna \& Moreno 2009). Positive, negative, and null effects of nitrates on germination of Mediterranean plants were found in these studies. This suggests a species-specific germination response to nitrates. However, the role of nitrates in the germination ecology of Mediterranean plants is poorly understood due to the contrasting results obtained. Therefore, more studies are still needed to better understand the role of nitrates in germination of plant species in the Mediterranean Basin.

In this study, we examined the germination responses of 12 eastern Mediterranean Basin species to different smoke and nitrate concentrations in laboratory conditions. We hypothesized that smoke and nitrate improve germination of the species studied. To test this hypothesis, seeds of each species were subjected to different concentrations of aqueous smoke solution, potassium nitrate $\left(\mathrm{KNO}_{3}\right)$ and ammonium nitrate $\left(\mathrm{NH}_{4} \mathrm{NO}_{3}\right)$. Germination percentages and mean germination times of each species were assessed, and the results were compared with those for the control conditions. By carrying out this experiment, we aimed to take a step towards filling the gaps in our knowledge on the role of nitrates and smoke as germination stimulants.

\section{Material and methods}

\section{Study species, study area and seed collection}

Seeds of 12 plant species were collected from fire-prone areas of Muğla Province, southwestern Turkey, eastern Mediterranean Basin (Table 1). The study region has a Mediterranean climate with mild, wet winters and hot, dry summers. Seeds were collected between July and September 2012, coinciding with the dispersal period of each species. Seeds were separated from fruit parts by hand and stored in paper envelopes at room temperature until the start of the experiment in January 2013. Mean seed mass was determined by weighing four samples of 100 seeds of each species.

\section{Preparation of smoke solutions}

Dry needles of Pinus brutia, a common tree species in the region, were used in preparation of smoke solutions. Four 5-g samples of this plant material were heated separately in glass flasks in the oven for $30 \mathrm{~min}$ at $195{ }^{\circ} \mathrm{C}$. The mouth of each flask was tightly covered with an aluminium foil to capture the smoke generated from the heated needles. Subsequently, $50 \mathrm{ml}$ of distilled water was poured over the heated material and left for 10 minutes (Çatav et al.2012). By this procedure, the active chemicals found in smoke are dissolved in water (Jäger et al. 1996). The solutions were filtrated from the flasks into a bottle to obtain a concentrated smoke solution ( $\mathrm{pH} 4.50$ ).

\section{The experiment}

The germination-medium compositions are given in Table 2. Twenty-five seeds of each 
species were sown directly in Petri dishes containing $20 \mathrm{ml}$ of the media. Each treatment consisted of four replicates. Petri dishes were then placed in an incubator at $20 \pm 1{ }^{\circ} \mathrm{C}$ in darkness. Previous studies showed that these conditions are favourable for germination of many Mediterranean-climate species (Bellairs \& Bell 1990, Luna et al. 2011). The seeds were checked for germination under a stereomicroscope every 2 days during the first 2 weeks, and then weekly until the end of the experiment. It should be noted that the seeds were exposed to daylight for short durations (10-20 minutes) during the germination checks. The criterion of germination was visible radicle protrusion. Germinated seeds were counted and removed from the Petri dishes at every check. The experiment was ended on the 35 th day of the incubation period, i.e. one week after last germination event had been recorded. Viability of non-germinated seeds was determined by a cutting test, and the seeds with and intact internal content were considered viable.

\section{Data analysis}

After removing empty seeds, the remaining seeds were then scored as germinated or non-germinated. For each species, the final proportion of germinated seeds in each treatment was compared with the control using the analysis of deviance with a binomial error distribution (Moreira

Table 1. Taxonomic status and ecological characteristics of the study species. GF is growth form (Ah = annual herb, $\mathrm{Bh}=$ biennial herb, $\mathrm{Ph}=$ perennial herb, $\mathrm{S}=$ shrub), and $\mathrm{SM}$ is mean seed mass in mg. RM is the post-fire regeneration mechanism and follows the Pausas et al. (2004) 'P \& R' system; P+ and P- indicate presence and absence, respectively, of propagule persistence after fire, while $\mathrm{R}+$ and $\mathrm{R}-$ refer to presence and absence, respectively, of post-fire resprouting ability. RM is based on Paula et al. (2009), Tavşanoğlu (2008), and field observations. Nomenclature follows Davis (1965-1985), and http://www.mobot.org/MOBOT/research/APweb/ for the current family names.

\begin{tabular}{|c|c|c|c|c|c|}
\hline Code & Family & Species & $\mathrm{RM}$ & GF & SM \\
\hline DBR & Apiaceae & Daucus broteri & $P+\& R-$ & $\mathrm{Ah}$ & 0.74 \\
\hline DCA & Apiaceae & Daucus carota & $\mathrm{P}+\& \mathrm{R}+$ & $\mathrm{Bh}$ & 1.03 \\
\hline SRO & Apiaceae & Smyrnium rotundifolium & unknown & $\mathrm{Bh}$ & 7.76 \\
\hline CDE & Asteraceae & Carthamus dentatus & $P+\& R-$ & $\mathrm{Ah}$ & 30.60 \\
\hline OCA & Asteraceae & Onopordum caricum ${ }^{\star}$ & $P+\& R-$ & $\mathrm{Bh}$ & 7.23 \\
\hline $\mathrm{ACA}$ & Brassicaceae & Alyssum caricum ${ }^{\star}$ & $P+\& R-$ & $\mathrm{S}$ & 0.43 \\
\hline AMI & Brassicaceae & Alyssum minus var. minus & $P-\& R-$ & $\mathrm{Ah}$ & 1.11 \\
\hline SVU & Caryophyllaceae & Silene vulgaris var. vulgaris & $\mathrm{P}-\& \mathrm{R}-$ & $\mathrm{Ph}$ & 1.88 \\
\hline HAV & Clusiaceae & $\begin{array}{l}\text { Hypericum aviculariifolium subsp. } \\
\text { aviculariifolium var. aviculariifolium }\end{array}$ & $P-\& R-$ & $\mathrm{Ph}$ & 0.28 \\
\hline $\mathrm{MCO}$ & Liliaceae & Muscari comosum & $\mathrm{P}-\& \mathrm{R}+$ & $\mathrm{Ph}$ & 4.52 \\
\hline $\mathrm{RCR}$ & Polygonaceae & Rumex crispus & $\mathrm{P}-\& \mathrm{R}-$ & $\mathrm{Ph}$ & 2.63 \\
\hline SSP & Rosaceae & Sarcopoterium spinosum & $P+\& R+$ & S & 3.15 \\
\hline
\end{tabular}

* endemic to Turkey.

Table 2. Media formulations. CSS = concentrated smoke solution. $\mathrm{pH}$ of germination media were adjusted using $0.1 \mathrm{M} \mathrm{HCl}$ or $0.1 \mathrm{M} \mathrm{NaOH}$.

\begin{tabular}{|c|c|c|c|c|c|}
\hline Treatment & Agar $\left(\mathrm{g} \mathrm{l}^{-1}\right)$ & $\operatorname{CSS}\left(\mathrm{ml} \mathrm{l}^{-1}\right)$ & $\mathrm{KNO}_{3}\left(\mathrm{~g} \mathrm{I}^{-1}\right)$ & $\mathrm{NH}_{4} \mathrm{NO}_{3}\left(\mathrm{~g} \mathrm{I}^{-1}\right)$ & $\mathrm{pH}$ \\
\hline Control & 10 & - & - & - & 5.8 \\
\hline Smoke 1:10 & 10 & 100 & - & - & 5.8 \\
\hline Smoke 1:100 & 10 & 10 & - & - & 5.8 \\
\hline $10 \mathrm{mM} \mathrm{KNO}_{3}$ & 10 & - & 1.01 & - & 5.8 \\
\hline $25 \mathrm{mM} \mathrm{KNO}_{3}$ & 10 & - & 2.53 & - & 5.8 \\
\hline $10 \mathrm{mM} \mathrm{NH}_{4} \mathrm{NO}_{3}$ & 10 & - & - & 0.8 & 5.8 \\
\hline $25 \mathrm{mM} \mathrm{NH}_{4}^{4} \mathrm{NO}_{3}$ & 10 & - & - & 2.0 & 5.8 \\
\hline
\end{tabular}


et al. 2010). Mean germination time (MGT, days) was determined using the following equation based on Tompsett \& Pritchard (1998): $\sum(n \times$ $D) / k$, where $n$ is the number of seeds that germinated on day $D, D$ is the number of days from the beginning of the incubation period, and $k$ is the total number of seeds that germinated during the incubation period. For each species, the differences between the mean germination time in the control and treatment groups were analyzed using one-way ANOVA followed by Dunnett's test for multiple comparisons. Homogeneity of variance was verified with Bartlett's test before each analysis. Because of the large number of pairwise comparisons, the significance level for all analyses was set at $p=0.01$. This approach is less conservative than the Bonferroni correction (Moran 2003), and has been effectively used in many studies in recent years (e.g. Moreira et al. 2010, Tavşanoğlu \& Gürkan 2014).

\section{Results}

The germination percentages in the controls varied among the study species, ranging from $0 \%$ to $100 \%$ (Table 3). In four species (Carthamus dentatus, Muscari comosum, Onopordum caricum, Smyrnium rotundifolium) the dormancy level was very high $(<6 \%$ germination in the control), whereas another four species (Alyssum caricum, A. minus, Rumex crispus, Silene vulgaris) had very low levels of dormancy (> 90\% germination in the control). Smoke and nitrate treatments failed to break high-level dormancy (zero germination in the control) in Muscari comosum and Smyrnium rotundifolium. Moreover, germination in the three species with no dormancy (Alyssum minus, Rumex crispus, Silene vulgaris) was not affected by any of the treatments (Table 3).

Smoke treatments resulted in a significant increase in germination of three species, but affected negatively germination of Hypericum aviculariifolium (Table 3). Of the 12 species studied, five showed significant improvement in germination after at least one of the nitrate treatments as compared with the control (Table 3). Regarding the effect of nitrates on germination, $10 \mathrm{mM} \mathrm{KNO}_{3}$ was the most effective treatment in which germination of five species was stimulated. The remaining nitrate treatments were the least effective ones, as germination of only two species was stimulated in each. However, none of the nitrate treatments affected germination of the study species negatively (Table 3 ).

Germination response of the species to smoke and nitrate treatments varied. Only in two species (Onopordum caricum and Sarcopoterium spinosum) germination was improved both by

Table 3. Mean germination percentages $( \pm S E)$ in the control, and in the smoke and nitrate treatments. For species codes see Table 1. In parentheses are $p$ values for pairwise comparisons of treatments with the control (analysis of deviance). Values that are significantly different from the control (at $p<0.01)$ are given boldface. "-" indicates that the treatment was not performed due to limited number of seeds.

\begin{tabular}{|c|c|c|c|c|c|c|c|}
\hline \multirow[t]{2}{*}{ Species } & \multirow[t]{2}{*}{ Control } & \multicolumn{2}{|c|}{ Smoke solution } & \multicolumn{2}{|c|}{$\mathrm{KNO}_{3}$} & \multicolumn{2}{|c|}{$\mathrm{NH}_{4} \mathrm{NO}_{3}$} \\
\hline & & $1: 10$ & $1: 100$ & $10 \mathrm{mM}$ & $25 \mathrm{mM}$ & $10 \mathrm{mM}$ & $25 \mathrm{mM}$ \\
\hline DBR & $28 \pm 6$ & $20 \pm 6$ (n.s.) & $34 \pm 4$ (n.s.) & $48 \pm 5(0.005)$ & $41 \pm 8$ (n.s.) & $24 \pm 4$ (n.s.) & $25 \pm 6$ (n.s.) \\
\hline DCA & $78 \pm 5$ & $93 \pm 3(0.003)$ & $80 \pm 5$ (n.s.) & $83 \pm 2$ (n.s.) & $83 \pm 5$ (n.s.) & $84 \pm 5$ (n.s.) & $85 \pm 3$ (n.s.) \\
\hline SRO & 0 & 0 & 0 & 0 & 0 & 0 & 0 \\
\hline CDE & $5 \pm 2$ & $10 \pm 7$ (n.s.) & - & $50 \pm 7(<0.001)$ & - & $35 \pm 7(<0.001)$ & - \\
\hline OCA & $3 \pm 1$ & $37 \pm 2(<0.001)$ & $18 \pm 3(<0.001)$ & $18 \pm 5(<0.001)$ & $25 \pm 4(<0.001)$ & $28 \pm 8(<0.001)$ & $35 \pm 6(<0.001)$ \\
\hline ACA & $92 \pm 3$ & $98 \pm 2$ (n.s.) & $98 \pm 1$ (n.s.) & $100 \pm 0(<0.001)$ & - & $94 \pm 2$ (n.s.) & - \\
\hline AMI & $100 \pm 0$ & $100 \pm 0$ (n.s.) & $100 \pm 0$ (n.s.) & $100 \pm 0$ (n.s.) & $100 \pm 0$ (n.s.) & $100 \pm 0$ (n.s.) & $100 \pm 0$ (n.s.) \\
\hline SVU & $100 \pm 0$ & $99 \pm 1$ (n.s.) & $100 \pm 0$ (n.s.) & $98 \pm 2$ (n.s.) & $100 \pm 0$ (n.s.) & $100 \pm 0$ (n.s.) & $100 \pm 0$ (n.s.) \\
\hline HAV & $48 \pm 7$ & $23 \pm 7(<0.001)$ & $23 \pm 14(<0.001)$ & $55 \pm 6$ (n.s.) & $47 \pm 4$ (n.s.) & $53 \pm 5$ (n.s.) & $60 \pm 1$ (n.s.) \\
\hline MCO & 0 & 0 & 0 & 0 & 0 & 0 & 0 \\
\hline RCR & $99 \pm 1$ & $99 \pm 1$ (n.s.) & $99 \pm 1$ (n.s.) & $99 \pm 1$ (n.s.) & $100 \pm 0$ (n.s.) & $99 \pm 1$ (n.s.) & $100 \pm 0$ (n.s.) \\
\hline SSP & $15 \pm 3$ & $68 \pm 5(<0.001)$ & $62 \pm 4(<0.001)$ & $39 \pm 6(<0.001)$ & $34 \pm 3(0.002)$ & $23 \pm 8$ (n.s.) & $32 \pm 3(0.005)$ \\
\hline
\end{tabular}


smoke and nitrate. The remaining species had different responses to smoke and nitrate treatments. For example, germination of Carthamus dentatus and Daucus broteri was enhanced by nitrate but not by smoke; inversely, germination percentage in Daucus carota was increased only by smoke. Nitrate applications did not decrease the germination percentage in comparison with that in the control in Hypericum aviculariifolium, the only species in which germination was negatively affected by smoke. An association between regeneration mechanism of species and their germination response to smoke and/ or nitrate treatments was found. That is, the species with germination enhanced by smoke and/ or nitrate were all propagule-persisters $(\mathrm{P}+)$, and non-stimulated species were all propagule nonpersisters $(\mathrm{P}-)$ except one in which regeneration mechanism is unknown (Table 3 ).

Apart from Daucus broteri in which MGT increased after a smoke treatment (1:100), smoke treatments did not significantly change MGT in the remaining species (Table 4). Sarcopoterium spinosum germinated significantly faster in the lower concentrations of nitrate than in the control. On the other hand, nitrate treatments resulted in slower germinations in Onopordum caricum and Daucus broteri. No significant changes in MGT were found in other species after the nitrate treatments.

\section{Discussion}

The smoke and nitrate treatments significantly increased the germination percentages in six of the 12 studied species (Alyssum caricum, Carthamus dentatus, Daucus broteri, D. carota, Onopordum caricum and Sarcopoterium spinosum). Of the study species, only germination of Hypericum aviculariifolium was negatively affected by smoke. As far as we know, our results provide the first evidence of smoke- and nitrate-stimulated germination in Onopordum caricum, which is endemic to Turkey. This result may have implications to in-situ and/or ex-situ conservation of endemic plants in Mediterranean vegetation in Turkey.

Availability of nitrogenous compounds can increase in the soil during the first rainy season following fire (Thanos \& Rundell 1995) and, in Mediterranean regions, prolific germination of many plants generally occurs during this period (Thanos \& Georghiou 1988, Bell et al. 1995). Consequently, many researchers focused on the role of nitrogenous compounds in post-fire germination (Thanos \& Rundel 1995, Bell et al. 1999, Henig-Sever et al. 2000). The results of those studies indicate that nitrate and ammonium can play an important role in germination of several plants (e.g., Emmenanthe penduliflora, Phacelia grandiflora). However, Keeley

Table 4. Mean ( \pm SE) mean germination times (days) in the control, and in the smoke and nitrate treatments. For species codes see Table 1. In parentheses are $p$ values for pairwise comparisons of treatments with the control (Dunnett's test). Values that are significantly different from the control (at $p<0.01)$ are given boldface. "-" indicates that MGT was not obtained due to either low germination percentage or the lack of treatment for the germination experiment.

\begin{tabular}{|c|c|c|c|c|c|c|c|}
\hline \multirow[t]{2}{*}{ Species } & \multirow[t]{2}{*}{ Control } & \multicolumn{2}{|c|}{ Smoke solution } & \multicolumn{2}{|c|}{$\mathrm{KNO}_{3}$} & \multicolumn{2}{|c|}{$\mathrm{NH}_{4} \mathrm{NO}_{3}$} \\
\hline & & $1: 10$ & $1: 100$ & $10 \mathrm{mM}$ & $25 \mathrm{mM}$ & $10 \mathrm{mM}$ & $25 \mathrm{mM}$ \\
\hline DBR & $4.5 \pm 0.3$ & $6.0 \pm 0.6$ (n.s.) & $9.3 \pm 2.0(0.0067)$ & $6.1 \pm 0.6$ (n.s.) & $11.7 \pm 1.6(0.0002)$ & $6.3 \pm 0.4$ (n.s.) & $10.3 \pm 1.5(0.0010)$ \\
\hline DCA & $5.6 \pm 0.1$ & $4.7 \pm 0.2$ (n.s.) & $4.9 \pm 0.4$ (n.s.) & $6.3 \pm 0.3$ (n.s.) & $6.1 \pm 0.2$ (n.s.) & $5.4 \pm 0.3$ (n.s.) & $5.5 \pm 0.2$ (n.s.) \\
\hline SRO & - & - & - & - & - & - & - \\
\hline CDE & $5.3 \pm 0.7$ & $4.0 \pm 0$ (n.s.) & - & $4.4 \pm 0.2$ (n.s.) & - & $4.3 \pm 0.1$ (n.s.) & - \\
\hline OCA & $2.0 \pm 0$ & $2.6 \pm 0.2$ (n.s.) & $3.2 \pm 0.4$ (n.s.) & $3.4 \pm 0.4$ (n.s.) & $3.4 \pm 0.2$ (n.s.) & $3.8 \pm 0.2(0.0062)$ & $4.0 \pm 0.1(0.0017)$ \\
\hline ACA & $2.1 \pm 0$ & $2.0 \pm 0$ (n.s.) & $2.0 \pm 0$ (n.s.) & $2.0 \pm 0$ (n.s.) & - & $2.1 \pm 0$ (n.s.) & - \\
\hline AMl & $2.0 \pm 0$ & $2.0 \pm 0$ (n.s.) & $2.0 \pm 0$ (n.s.) & $2.0 \pm 0$ (n.s.) & $2.0 \pm 0$ (n.s.) & $2.0 \pm 0$ (n.s.) & $2.0 \pm 0$ (n.s.) \\
\hline SVU & $2.1 \pm 0.1$ & $2.1 \pm 0.1$ (n.s.) & $2.1 \pm 0.1$ (n.s.) & $2.0 \pm 0$ (n.s.) & $2.0 \pm 0$ (n.s.) & $2.0 \pm 0$ (n.s.) & $2.0 \pm 0$ (n.s.) \\
\hline HAV & $8.5 \pm 0.2$ & $8.7 \pm 0.3$ (n.s.) & $8.4 \pm 0.9$ (n.s.) & $9.2 \pm 0.4$ (n.s.) & $9.5 \pm 0.3$ (n.s.) & $8.2 \pm 0.4$ (n.s.) & $8.4 \pm 0.2$ (n.s.) \\
\hline $\mathrm{MCO}$ & - & - & - & - & - & - & - \\
\hline RCR & $2.4 \pm 0.1$ & $2.5 \pm 0.1$ (n.s.) & $2.4 \pm 0.1$ (n.s.) & $2.6 \pm 0.2$ (n.s.) & $3.0 \pm 0.3$ (n.s.) & $2.4 \pm 0.1$ (n.s.) & $2.5 \pm 0.1$ (n.s.) \\
\hline SSP & $16.1 \pm 1.5$ & $11.9 \pm 0.5$ (n.s.) & $13.3 \pm 0.8$ (n.s.) & $9.6 \pm 0.8(0.0039)$ & $11.9 \pm 2.0$ (n.s.) & $9.9 \pm 0.7(0.0067)$ & $10.7 \pm 1.1(0.0235)$ \\
\hline
\end{tabular}


and Fotheringham (1998) reported that $\mathrm{KNO}_{3}$ solutions indeed stimulate germination in E.penduliflora and $P$. grandiflora, but only at low $\mathrm{pH}$. Accordingly, they proposed that both oxidizing gases in smoke and acids are potential germination triggers for these post-fire annuals. On the other hand, Pérez-Fernández et al. (2006) showed that germination of their study species (mainly herbaceous plants) was not affected by the concentration of $\mathrm{H}^{+}$with or without the nitrate ion. Although our study cannot be compared with the above ones since our experimental design did not include a $\mathrm{pH}$ gradient, our results indicate that germination success of species is variable in smoke and nitrate treatments at the same $\mathrm{pH}$ level (in our case $\mathrm{pH}=5.8$ ).

The mechanism of improving seed germination by nitrogenous compounds was investigated by Henig-Sever et al. (2000). The results of their study suggest that nitrate increases the seed sensitivity to $\mathrm{GA}_{3}$ (gibberellic acid), whereas ammonium directly affects lipase activity. Germination induction by nitrates is achieved in the concentration range up to $50 \mathrm{mM}$, while higher concentrations have a negative effect (Thanos \& Rundel 1995, Bell et al. 1999, Pérez-Fernández \& Rodríguez-Echeverría 2003). The concentrations we applied in our study were within this range, so this could explain why we found no negative effects of any nitrate treatment on the germination of the studied species.

The association between the capacity to recruit after fire $(\mathrm{P}+, \mathrm{P}-)$ and germination response of species suggests that smoke- and nitrate-stimulated germination are important determinants of the regeneration strategy in Mediterranean plants. In the Mediterranean Basin, fire-prone plant communities are phylogenetically and phenotypically clustered as a result of the filtering processes of fire proceeding on the species that have fire-persistent traits (Pausas \& Verdú 2008). It has been shown that flammability-enhancing traits in post-fire seeders $(\mathrm{P}+)$ vary adaptively in response to fire (Moreira et al. 2014) by producing the necessary cues for triggering germination from the seed bank and opening spaces for the regeneration of the offspring (Pausas \& Moreira 2012). Moreover, propagule persistence $(\mathrm{P}+)$ is an evolutionaryconserved trait at the genus and family levels since the appearance of Mediterranean climate in the region (Verdú \& Pausas 2007). Therefore, many families in which $\mathrm{P}+$ trait is observed include species with enhanced post-fire germination (Çatav et al. 2014) and post-fire establishment (Tavşanoğlu \& Gürkan 2014). Paula and Pausas (2008) also demonstrated the higher capacity of fire stimulated germination in nonresprouters $(\mathrm{R}-)$ than in resprouters $(\mathrm{R}+)$. However, since our study included just a dozen species, the results on regeneration mechanism should be considered carefully.

In summary, our results reveal that both smoke and nitrate play a role in germination stimulation of Mediterranean species, at least for the subset of the studied species. Our results also suggest the presence of species-specific germination response to smoke and nitrates in Mediterranean plants.

\section{Acknowledgments}

The seeds were collected in the field with the permission of the Ministry of Food, Agriculture and Livestock of Republic of Turkey (no: 1379, date: 09.03.2012). The experiments were conducted in the laboratories of Department of Biology, Muğla University, Turkey. The fieldwork of this study was supported by Hacettepe University Scientific Research Unit (project no. 012.D06.601.0013).

\section{References}

Arianoutsou-Faraggitaki M. \& Margaris N.S. 1982: Decomposers and the fire cycle in a phryganic (East Mediterranean) ecosystem. - Microbial Ecol. 8: 91-98.

Bell D.T., King L.A. \& Plummer J.A. 1999: Ecophysiological effects of light quality and nitrate on seed germination in species from Western Australia. - Aust. J. Ecol. 24: $2-10$

Bell D.T., Rokich D.P., McChesney C.J. \& Plummer J.A. 1995: Effects of temperature, light and gibberellic acid on the germination of seeds of 43 species native to Western Australia. - J. Veg. Sci. 6: 797-806.

Bellairs S.M. \& Bell D.T. 1990: Temperature effects on the seed-germination of 10 kwongan species from Eneabba, western-Australia. - Aust. J. Ecol. 38: 451-458.

Christensen N.L. 1994: The effects of fire on physical and chemical properties of soils in Mediterranean-climate shrublands. - In: Moreno J.M. \& Oechel W.C. (eds.), The role of fire in Mediterranean-type ecosystems: 79-95. Springer, New York.

Cowling R.M., Rundel P.W., Lamont B.B., Arroyo M.K. \& 
Arianoutsou M. 1996: Plant diversity in Mediterraneanclimate regions. - Trends Ecol. Evol. 11: 362-366.

Crosti R., Ladd P.G., Dixon K.W. \& Piotto B. 2006: Post-fire germination: The effect of smoke on seeds of selected species from the central Mediterranean basin. - Forest Ecol. Manage. 221: 306-312.

Çatav Ş.S., Bekar İ., Ateş B.S., Ergan G., Oymak F., Ülker E.D. \& Tavşanoğlu Ç. 2012: Germination response of five eastern Mediterranean woody species to smoke solutions derived from various plants. - Turkish J. Bot. 36: $480-487$.

Çatav Ş.S., Küçükakyüz K., Akbaş K. \& Tavşanoğlu Ç. 2014: Smoke-enhanced seed germination in Mediterranean Lamiaceae. - Seed Sci. Res. 24: 257-264.

Davis P.H. 1965-1985: Flora of Turkey and the East Aegean Islands, vols. 1-9. - Edinburgh University Press, Edinburgh.

De Lange J.H. \& Boucher C. 1990: Autecological studies on Audouinia capitata (Bruniaceae). I. Plant-derived smoke as a seed germination cue. - S. Afr. J. Bot. 56: 700-703.

Dixon K.W., Roche S. \& Pate J.S. 1995: The promotive effect of smoke derived from burnt native vegetation on seed germination of Western Australian plants. - Oecologia 101: 185-192.

Doussi M.A. \& Thanos C.A. 1997: Ecophysiology of seed germination in composites inhabiting fire-prone Mediterranean ecosystems. - In: Ellis R., Black M., Murdoch A. \& Hong T. (eds.), Basic and applied aspects of seed biology: 641-649. Kluwer Academic Publishers, Great Britain.

Henig-Sever N., Eshel A. \& Ne'eman G. 2000: Regulation of the germination of Aleppo pine (Pinus halepensis) by nitrate, ammonium, and gibberellin, and its role in post-fire forest regeneration. - Physiol. Plantarum 108: 390-397.

Herranz J.M., Ferrandis P. \& Martínez-Sánchez J.J. 1998: Influence of heat on seed germination of seven Mediterranean Leguminosae species. - Plant Ecol. 136: 95-103.

Jäger A.K., Light M.E. \& Van Staden J. 1996: Effects of source of plant material and temperature on the production of smoke extracts that promote germination of light-sensitive lettuce seeds. - Environ. Exp. Bot. 36: 421-429.

Keeley J.E. 1993: Smoke-induced flowering in the fire-lily Cyrtanthus ventricosus. - S. Afr. J. Bot. 59: 638.

Keeley J.E. \& Bond W.J. 1997: Convergent seed germination in South African fynbos and Californian chaparral. Plant Ecol. 133: 153-167.

Keeley J.E., Bond W.J., Bradstock R.A., Pausas J.G. \& Rundel P.W. 2012: Fire in Mediterranean ecosystems: ecology, evolution and management. - Cambridge University Press, Cambridge.

Keeley J.E. \& Fotheringham C.J. 1998: Mechanism of smoke-induced seed germination in a post-fire chaparral annual. - J. Ecol. 86: 27-36.

Keeley J.E., Morton B.A., Pedrosa A. \& Trotter P. 1985: Role of allelopathy, heat and charred wood in the germination of chaparral herbs and suffrutescents. - J. Ecol. 73: $445-458$.
Keeley J.E., Pausas J.G., Rundel P.W., Bond W.J. \& Bradstock R.A. 2011: Fire as an evolutionary pressure shaping plant traits. - Trends Plant Sci. 16: 406-411.

Luna B. \& Moreno J.M. 2009: Light and nitrate effects on seed germination of Mediterranean plant species of several functional groups. - Plant Ecol. 203: 123-135.

Luna B., Pérez B., Torres I. \& Moreno J.M. 2012: Effects of incubation temperature on seed germination of Mediterranean plants with different geographical distribution ranges. - Folia Geobot. 47: 17-27.

Moran M.D. 2003: Arguments for rejecting the sequential Bonferroni in ecological studies. - Oikos 100: 403-405.

Moreira B. \& Pausas J.G. 2012: Tanned or burned: the role of fire in shaping physical seed dormancy. - PloS One 7(12): e51523, doi:10.1371/journal.pone.0051523.

Moreira B., Tormo J., Estrelles E. \& Pausas J.G. 2010: Disentangling the role of heat and smoke as germination cues in Mediterranean Basin flora. - Ann. Bot. 105: 627-635.

Moreira B., Castellanos M.C. \& Pausas J.G. 2014: Genetic component of flammability variation in a Mediterranean shrub. - Mol. Ecol. 23: 1213-1223.

Papenfus H.B., Kumari A., Kulkarni M.G., Finnie J.F. \& Van Staden J. 2014: Smoke-water enhances in vitro pollen germination and tube elongation of three species of Amaryllidaceae. - S. Afr. J. Bot. 90: 87-92.

Paula S. \& Pausas J.G. 2008: Burning seeds: germinative response to heat treatments in relation to resprouting ability. - J. Ecol. 96: 543-552.

Pausas J.G., Bradstock R.A., Keith D.A. \& Keeley J.E. 2004: Plant functional traits in relation to fire in crown-fire ecosystems. - Ecology 85: 1085-1100.

Pausas J.G. \& Moreira B. 2012: Flammability as a biological concept. - New Phytol. 194: 610-613.

Pausas J.G. \& Verdú M. 2008: Fire reduces morphospace occupation in plant communities. - Ecology 89: 21812186.

Pérez-Fernández M.A. \& Rodríguez-Echevarría S. 2003: Effect of smoke, charred wood, and nitrogenous compounds on seed germination of ten species from woodland in central-western Spain. - J. Chem. Ecol. 29: 237-251.

Pérez-Fernández M.A., Calvo-Magro E., Montanero-Fernández J. \& Oyola-Velasco J.A. 2006: Seed germination in response to chemicals: Effect of nitrogen and $\mathrm{pH}$ in the media. - J. Environ. Biol. 27: 13-20.

Reyes O. \& Trabaud L. 2009: Germination behaviour of 14 Mediterranean species in relation to fire factors: smoke and heat. - Plant Ecol. 202: 113-121.

Rundel P.W. 1982: Nitrogen utilization efficiencies in mediterranean-climate shrubs of California and Chile. Oecologia 55: 409-413.

Senaratna T., Dixon K., Bunn E. \& Touchell D. 1999: Smoke-saturated water promotes somatic embryogenesis in geranium. - Plant Growth Regul. 28: 95-99.

Stock W.D. \& Lewis O.A.M. 1986: Soil nitrogen and the role of fire as a mineralizing agent in a South African coastal fynbos ecosystem. - J. Ecol. 74: 317-328.

Tavşanoğlu Ç. 2008: Post-fire vegetation dynamics of Pinus 
brutia (Turkish red pine) forests of Marmaris region. Ph.D. thesis, Hacettepe University, Ankara.

Tavşanoğlu Ç. \& Gürkan B. 2014: Long-term post-fire dynamics of co-occuring woody species in Pinus brutia forests: the role of regeneration mode. - Plant Ecol. 215: 355-365.

Thanos C.A. \& Georghiou K. 1988: Ecophysiology of firestimulated seed germination in Cistus incanus ssp. creticus (L.) Heywood and C. salvifolius L. - Plant Cell Environ. 11: 841-849.

Thanos C.A., Georghiou K., Kadis C. \& Pantazi C. 1992: Cistaceae: a plant family with hard seeds. - Israel $J$. Bot. 41: 251-263.

Thanos C.A. \& Rundel P.W. 1995: Fire-followers in chaparral: nitrogenous compounds trigger seed germination. J. Ecol. 83: 207-216.

Tompsett P.B. \& Pritchard H.W. 1998: The effect of chilling and moisture status on the germination, desiccation tolerance and longevity of Aesculus hippocastanum L. seed. - Ann. Bot. 82: 249-261.

Tormo J., Moreira B. \& Pausas J.G. 2014: Field evidence of smoke-stimulated seedling emergence and establishment in Mediterranean Basin flora. - J. Veg. Sci. 25: 771-777.

Van Staden J., Sparg S.G., Kulkarni M.G. \& Light M.E. 2006: Post-germination effects of the smoke-derived compound 3-methyl-2H-furo[2,3-c]pyran-2-one, and its potential as a preconditioning agent. - Field Crop Res. 98: 98-105.

Verdú M. \& Pausas J.G. 2007: Fire drives phylogenetic clustering in Mediterranean Basin woody plant communities. - J. Ecol. 95: 1316-1323.

Wisheu I.C., Rosenzweig M.L., Olsvig-Whittaker L. \& Shmida A. 2000: What makes nutrient-poor mediterranean heathlands so rich in plant diversity? - Evol. Ecol. Res. 2: 935-955. 